\title{
EVALUASI SISTEM MANAJEMEN MUTU PRODUK RAJUNGAN “VALUE ADDED" UNTUK MEGURANGI KOMPLAIN KONSUMEN DI PABRIK PENGOLAHAN RAJUNGAN VALUE ADDED LAMPUNG
}

\section{The Evaluation of Product Quality Management System Small Crab Attaching "Value Added" to the Consumer Complaint Reduces at Crab Value Added Processing Plants in Lampung Province}

\author{
Okta Amelia \\ Institut Teknologi Sumatera, Jl. Terusan Ryacudu Desa Way Hui Lampung Selatan, Indonesia \\ e-mail: okta.amelia@tin.itera.ac.id
}

Diterima: 29 Oktober 2018, Direvisi: 3 Desember 2018, Disetujui: 5 Desember 2018

\begin{abstract}
Abstrak
Pabrik pengolahan rajungan di Propinsi Lampung telah menerapkan Sistem Manajemen Mutu Produk (SMMP) dengan penerapan Hazard Analysis Critical Control Point (HACCP) sejak tahun 1998. Walaupun telah menerapkan SMMP, pabrik tersebut masih dikomplain oleh konsumennya karena mutu produk hasil olahannya. Tujuan penelitian ini yaitu mengevaluasi SMMP "value added" rajungan (Portunus pelagicus) dan menerapkan strategi perbaikan SMMP untuk mengurangi komplain konsumen. Penelitian ini bersifat studi kasus dan metode yang digunakan adalah metode wawancara dan penyebaran kuesioner. Evaluasi SMMP dilakukan dengan cara pengamatan dan wawancara langsung terhadap atasan yang berkaitan langsung atas berjalannya penerapan HACCP yaitu manajer produksi dan QA untuk mengumpulkan informasi tentang sistem penjamin mutu dalam industri olahan rajungan. Penelitian ini dibagi menjadi 2 tahap yaitu tahap evaluasi SMMP dan tahap implementasi hasil evaluasi SMMP. Evaluasi SMMP menghasilkan 3 prioritas perbaikan SMMP yang dianalisa dengan metode AHP. Tiga prioritas tersebut yaitu (1) memperbaiki sarana dan prasarana ruang produksi sesuai dengan persyaratan Hazard Analysis Critical Control Point (HACCP) khususnya penambahan lampu UV untuk memudahkan pengecekkan serpihan benda asing agar tidak terikut dalam daging rajungan, (2) memotivasi seluruh karyawan untuk bekerja mengikuti SMMP yang telah diperbaiki secara ketat, dan (3) memonitor dan mengevaluasi hasil kerja seluruh karyawan sesuai dengan SMMP yang telah diperbaiki. Sejak implementasi 3 prioritas SMMP tersebut, komplain konsumen tidak terjadi lagi selama enam bulan terakhir. Hal ini menunjukkan bahwa perusahaan dapat menghindari kerugian finansial yang berasal dari klaim akibat komplain konsumen sebesar Rp. 400.000 .000 (empat ratus juta rupiah) lebih per tahun.
\end{abstract}

Kata kunci: SMMP, HACCP, rajungan

\begin{abstract}
Small crab attaching processing plant in Lampung Province has implemented a quality management system products (SMMP) with the application of Hazard Analysis Critical Control Point (HACCP) since 1998. Although it has been applying the SMMP, the factory is still complained by its customers because product quality petrol results. The purpose of the study is to evaluate the SMMP "value added" (Portunus pelagicus) small crab attaching to devise and implement a strategy to reduce the SMMP repair consumer complaints. This research is both case studies and the methods used are interviews and dissemination of the questionnaire. Evaluation of the SMMP is done by means of observation and interviews directly against the employer concerned directly upon the passage of the application of HACCP namely production manager and QA system to gather information about the guarantor of quality in the industry of processed small crab attaching. This research is divided into two stages, namely the stage of evaluation of the SMMP implementation stages and results of evaluation of the SMMP. Evaluation of the SMMP have results 3 priority repair SMMP analysed by the method of AHP. These three priorities are (1) to improve the infrastructure of production space in accordance with the requirements of the Hazard Analysis Critical Control Point (HACCP) in particular the addition of a UV lamp for easy checking foreign object debris so as not shipped in the flesh, (2) small crab attaching to motivate all employees to work following the SMMP is strictly fixed, and (3) monitor and evaluate the work of all employees in accordance with the SMMP is fixed. Since the implementation of 3 the SMMP, priorities consumers complain does not occur again during the last six months. This shows that companies can avoid financial losses stemming from claims due to consumer complaints of 400 million rupiah (four hundred million dollars) more per year.
\end{abstract}

Keyword: SMMP, HACCP, small crab attaching 


\section{PENDAHULUAN}

Salah satu produk olahan rajungan yaitu produk value added rajungan. Ekspor produk value added rajungan di salah satu pabrik olahan rajungan di Lampung pada tahun 2014 sebanyak 1.137 ton dan pada tahun 2015 naik menjadi 1.431 ton. Pada tahun 2016, pabrik olahan rajungan ini memiliki target ekspor kurang lebih 2000 ton. Walaupun telah menerapkan sistem penjamin mutu sejak tahun 1998, pabrik rajungan ini masih mengalami komplain konsumen.

Komplain konsumen pada produk value added rajungan di tahun 2013-2016 sebanyak 106 komplain yang dikategorikan sebagai komplain keamanan pangan sebanyak 32 dan kualitas produk sebanyak 74 yang terdiri dari ketidaksesuaian produk dan benda asing pada produk yang kerugiannya sebesar Rp 1.961.113.410.

Penyebab komplain produk value added rajungan dapat berasal dari sistem manajemen mutu, sarana dan prasarana, SDM, serta pengendalian mutu yang tidak sesuai

Komplain konsumen disebabkan oleh komponen fisik yang seharusnya tidak ada dalam pangan. Pada kasus pangan yang terkontaminasi rambut, pecahan plastik, pecahan kayu, bahkan potongan besi pada makanan siap konsumsi, hal ini akan sangat bahaya jika ikut dikonsumsi konsumen.

Menurut Basith et.al (2013), timbulnya penolakan produk dapat disebabkan oleh faktor internal dan faktor eksternal perusahaan yang mempengaruhi mutu produk yang dihasilkan. Munculnya penolakan produk karena produk yang dihasilkan tidak sesuai keinginan konsumen. Tolakan yang menjadi perhatian dalam penerapan sistem HACCP adalah tolakan mengenai mutu dan tolakan yang dapat berpotensi menjadi bahaya pangan diantaranya adanya perubahan warna, dan adanya benda asing pada produk. Menurut Herdiana (2015), berkembangnya keanakaragaman pangan dari produk perikanan membuat munculnya sistem manajemen mutu untuk keamanan pangan dunia termasuk produk perikanan.

HACCP merupakan salah satu Food Safety Management System yang diakui secara internasional oleh lembaga keamanan pangan sebagai pedoman di seluruh dunia untuk mengendalikan bahaya keamanan yang berkaitan dengan makanan (Dimitrios et al , 2013). Penerapan HACCP harus diterapkan di seluruh rantai makanan untuk mengendalikan masa simpan produk dan proses produksi. Prosedur sederhana pengendalian proses misalnya saja dengan melakukan kalibrasi peralatan. Sebuah sistem yang dijalankan berdasarkan saran dari seorang ahli yang kemudian didokumentasikan menjadi cara yang tepat untuk mengaplikasikan HACCP (CAC, 2003).

Menurut Jadi (2016), parameter keamanan pangan pada tahap akhir proses produksi di UKM agri-food antara lain tingkat penggunaan sistem HACCP, panjang interval antara pembaruan sistem, pelatihan staf pada Good Manufacturing Practices (GMP), komitmen tim manajemen, dan kesediaan staf untuk mematuhi aturan dan persyaratan HACCP. Jika proses produksi di UKM menerapkan HACCP persentase produk yang tidak sesuai dapat diminimalisir.

Perkembangan industri pangan yang tidak diiringi peningkatan mutu produk dan penjaminan mutu produk agar aman untuk dikonsumsi, akan merugikan keberadaan industri tersebut. Salah satunya adalah hilangnya kepercayaan konsumen yang diakibatkan oleh penurunan mutu dan menimbulkan bahaya terhadap produk. Agar mutu dan kemanan produk tetap dapat dipertahankan dan ditingkatkan, diperlukan peningkatan terhadap sumber daya yang terlibat di dalamnya serta sistem yang menjamin mutu dan keamanan produk industri pangan tersebut (Daulay, 2016).

Rafeeque (2017), menyatakan industri makanan harus menerapkan dan memelihara sistem manajemen keamanan pangan yang berbeda sesuai standar Food Safety Management System (FSMS) yang mengikuti persyaratan customer dan pasar untuk memastikan bahwa keamanan produk sesuai dengan keinginan konsumen. Grigg dan McAlinden (2001) menyatakan bahwa ada peningkatan permintaan pelanggan pada industri di Inggris untuk mengadopsi standar keamanan pangan seperti BRC Global Standar. . Meurut Sutresni (2016) faktor yang menjadi prasyarat keefektifan penerapan HACCP sebagai sebuah sistem pengendalian mutu adalah terpenuhinya persyaratan kelayakan dasar (GMP dan SSOP) strategi penerapan HACCP.

\section{TINJAUAN PUSTAKA}

\subsection{Sistem Penjaminan Mutu}

Penerapan sistem manajemen mutu di perusahaan atas dasar dari kebutuhan akan keamanan pangan yang merupakan tuntutan akan keamanan pangan di masyarakat saat ini. Sistem manajemen mutu yang berupa HACCP 
merupakan salah satu bukti konsekuensi dari perusahaan untuk selalu mengutamakan kebutuhan konsumen yang menginginkan produk dengan kualitas yang baik. HACCP merupakan salah satu rencana mutu yang dirancang oleh departemen QA (Quality Assurance) dan dijalankan oleh QC (Quality Control) pada industri rajungan. Departemen QA dan QC bertanggung jawab terhadap jaminan mutu perusahaan termasuk HALAL, GMP, SSOP, BRC7 dan HACCP pada perusahaan.

Untuk menanggulangi bahaya keamanan pangan perusahan menerapkan sistem jaminan mutu keamanan pangan HACCP dengan mengevaluasi kemungkinan terjadinya bahaya dan mengendalikan bahayabahaya yang terjadi pada produk. Sistem HACCP pada perusahaan juga menjabarkan secara rinci tindakan-tindakan perbaikan yang terjadi jika bahaya keamanan pangan terjadi pada produk, sehingga mengecilkan kemungkinan terjadinya produk cacat yang terlanjur sampai ke pihak konsumen (Sutrisno, 2013).

Menurut Hadiwiardjo et al. (2000), sistem manajemen mutu merupakan suatu sarana yang berpotensi untuk memperbaiki kondisi perdagangan dan mutu produk pertanian. Sistem ini melibatkan upaya pola pengelolaan dalam suatu industri baik yang menyangkut pengadaan bahan baku, operasionalisasi teknologi, kompetensi personil, dokumentasi mutu dan sebagainya. Menurut Puspitasari et al. (2012), salah satu bentuk pendekatan sistem manajemen mutu adalah BRC, HACCP (Hazard Analysis Critical Control Point) termasuk di dalamnya GMP maupun SSOP.

\subsection{Good Manufacturing Practice (GMP)}

Good Manufacturing Practice (GMP) merupakan pedoman cara berproduksi pangan yang bertujuan supaya produsen pangan memenuhi persyaratan-persyaratan yang telah ditentukan untuk menghasilkan produk pangan yang bermutu dan aman dikonsumsi sesuai dengan tuntutan konsumen. GMP wajib diterapkan oleh industri yang menghasilkan produk pangan sebagai upaya preventif agar pangan yang siap dikonsumsi tersebut bersifat aman, layak, dan berkualitas (Anggraini dan Yudhatuti, 2014).

Prinsip dasar dari GMP adalah bahwa mutu dibangun di dalam produk, dan tidak hanya diuji pada produk akhir saja. Penjaminan mutu terhadap produk tidak semata-mata untuk mendapatkan spesifikasi akhir yang diinginkan, tapi penjaminan mutu dilakukan dengan cara membuat produk dengan prosedur tertentu dalam masing-masing kondisi yang sama. Good Manufacturing Practices lebih berperan dalam proses produksi karena elemen-elemen dalam GMP merupakan elemen-elemen sistem produksi (Hermansyah et al., 2013).

\subsection{Sanitation Standard Operating Procedure (SSOP)}

Sanitation Standard Operating System (SSOP) merupakan suatu prosedur untuk memelihara kondisi sanitasi yang umumnya berhubungan dengan seluruh fasiltas produksi atau area perusahaan dan tidak terbatas pada tahapan tertentu. Sanitasi merupakan cara pencegahan penyakit dengan mengatur atau menghilangkan faktor-faktor lingkungan yang saling terkait dalam rantai kontaminasi silang (Fachry et al., 2013).

\subsection{Hazard Analytical Critical Control Point (HACCP)}

Hazard Analysis Critical Control Point (HACCP) adalah suatu prosedur untuk mengidentifikasi, menilai, dan mengontrol bahaya-bahaya, secara langsung beresiko yang berasal dari makanan. Semua jenis makanan yang menyebabkan penyakit manusia atau yang lebih dikenal dengan istilah food borne disease, apapun penyebabnya (Redmond dan Griffith, 2003).

HACCP direkomendasikan oleh organisasi kesehatan dunia (WHO) dan Codex Alimentarius untuk digunakan dalam industry makanan. HACCP bersifat preventif sesuai kebutuhan oleh perusahaan dan diterapkan berdasarkan sistem yang ada di industri sehingga lebih kompleks dalam melaksanakan dan pengendaliannya. HACCP kini telah menjadi bagian penting dari semua standar keamanan pangan yang diterima secara internasional (Ababio, 2015). Industry pengolahan makanan dan minuman, penerapan sistem keamanan pangan yang meliputi cara produksi pangan yang baik (GMP), sanitasi, dan HACCP memiliki peranan yang sangat penting (Surahman dan Riyanti, 2014).

Setiap sistem HACCP mengakomodasi perubahan seperti kemajuan dalam rancangan peralatan, prosedur pengolahan atau perkembangan teknologi. HACCP dapat diterapkan pada seluruh rantai pangan dari produk primer sampai pada konsumsi akhir dan penerapannya harus dipedomani dengan bukti secara ilmiah terhadap resiko kesehatan manusia. Selain meningkatkan keamanan pangan, penerapan HACCP dapat membantu inspeksi oleh lembaga yang berwenang dan memajukan perdagangan internasional, melalui 
peningkatan kepercayaan keamanan pangan (Beyza dan Canan, 2013).

HACCP merupakan sebuah system yang sangat baik yang harus dijalankan dan diimplementasikan kepada semua negara yang memproduksi produk perikanan. Hal ini dikarenakan sistem HACCP dapat menjaga volume produktifitas bersamaan dengan kualitas dan kemanan pangan yang dihasilkan (Sherif, 2013). Faktor penunjang yang menjadi pra-syarat keefektifan penerapan HACCP sebagai sebuah sistem pengendalian mutu adalah terpenuhinya persyaratan kelayakan dasar (GMP dan SSOP). Untuk itu perlu diketahui tingkat penerapan kelayakan dasar (GMP dan SSOP), tingkat penerapan HACCP serta strategi penerapan HACCP (Sutresni, 2016). Sebelum penerapan HACCP terlebih dahulu menerapkan Good Manufacturing Practises (GMP) dan Sanitation Standard Operating Procedure (SSOP) sebagai persyaratan dasar telah sebelum penerapan HACCP, dan dilakukan 5 langkah penerapan HACCP, yakni pembentukan tim HACCP, menyusun deskripsi produk, menetapkan pengguna akhir, menyusun diagram alir, dan melakukan verifikasi terhadap diagram alir yang disusun (Tsaniyah, 2015). Pendekatan HACCP ini akan membantu dalam perencanaan berbagai kegiatan keamanan pangan yang memusatkan perhatian pada berbagai bahaya yang berhubungan dengan jenis makanan yang dikonsumsi dan makanan yang diolah dan disiapkan (Sudibyo et al, 2016).

Menurut Fathonah (2005), di dalam penerapannya, Hazard Analysis and Critical Control Point memiliki beberapa prinsip yang dilaksanakan yaitu melakukan analisa bahaya, menentukan titik pengendalian kritis, menentukan batas kritis, pemantauan titik kendali kritis, melakukan tindakan korektif, menetapkan prosedur verifikasi, dan melakukan dokumentasi terhadap seluruh prosedur dan catatan.

\subsection{Pengembangan Sitem Penjaminan Mutu}

Pelaksanaan risk analysis sebagai dasar pengembangan kebijakan, persyaratan teknis dan pengawasan manajemen mutu dan keamanan pangan merupakan salah satu komponen yang belum mampu dilakukan oleh beberapa negara tujuan ekspor dan Indonesia. Uni Eropa, Amerika Serikat dan Kanada yang menerapkan kaidah risk analysis secara benar. Uni Eropa melakukan risk analysis melalui European Food Safety Authority, Amerika Serikat melalui Center for Food and Applied Nutrient dan beberapa lembaga lainnya, dan
Kanada melalui Council of Science and Technology Advisor. Pelaksanaan risk analysis juga sudah dilaksanakan dengan mengikuti kaidah yang direkomendasikan oleh Codex, yaitu melalui tahapan risk assesment, risk management dan risk communication. Selain itu, hasil dan dokumen risk analysis sudah terdokumentasikan dengan baik (Trilaksani, 2011).

\section{METODE PENELITIAN}

Penelitian ini dilakukan di salah satu Pabrik Pengolahan Rajungan Lampung, Maret 2017 sampai dengan Juni 2017. Perusahaan dipilih karena satu-satunya yang memproduksi value added rajungan di Lampung. Penelitian ini bersifat studi kasus dan metode yang digunakan adalah metode wawancara dan penyebaran kuesioner. Pengamatan dan wawancara langsung dengan manajer produksi dan QA untuk mengumpulkan informasi tentang sistem penjamin mutu dalam industri olahan rajungan. Informasi yang didapat digunakan sebagai dasar untuk menyiapkan instrumen kuesioner. Selain informasi tersebut variabel pelaksanaan sistem penjamin mutu dijadikan sebagai instrumen kuesioner.

Informasi yang didapat digunakan sebagai dasar instrumen kuesioner AHP untuk mecapai tujuan dari penelitian. Variabel pelaksanaan HACCP dijadikan sebagai dasar instrumen kuesioner. Hal ini menghasilkan 4 kriteria pembanding yang terdiri dari faktor, aktor, tujuan, dan alternatif strategi.

Penelitian ini tediri dari dua tahap yaitu memberikan dan meminta responden mengisi kuesioner AHP kepada 9 orang pakar top management yang bekerja di pabrik tersebut untuk menentukan peringkat dari hasil strategi yang dan mengolah hasil AHP untuk menentukan prioritas strategi peningkatan penerapan SMMP. Strategi yang didapat dijadikan sebagai alternatif pada metode AHP untuk menentukan pemeringkatan. Kuesioner AHP yang diisi oleh responden dengan menggunakan metode pairwase comparisson . Responden diperoleh dari berbagai lapisan level manajemen pada perusahaan berdasarkan tingkat pemahaman karyawan mengenai penerapan sistem mutu HACCP. Responden top management berasal dari QMR (Quality Management Review), QA dan QC (Quality Assurance dan Quality Qontrol) Section Head, QA Manager, Production Manager, Production Section Head, Technique Manager, Operational Manager, General Manager, Metode ini membandingkan antara komponen 
dengan skala 1-9. Hasil data perbandingan diolah dengan menggunakan program expert Choice 11.

\section{HASIL DAN PEMBAHASAN}

Analisis AHP digunakan untuk mengetahui strategi yang paling cocok untuk diterapkan di perusahaan. Metoda AHP dapat diterapkan pada sejumlah besar proses pengambilan keputusan. Pendekatan yang diambil adalah dengan membentuk model evaluasi dan memberikan bobot-bobot terhadap kriteriakriteria yang ada.

\section{a. Penyusunan Faktor Hierarki}

Penyusunan hierarki dilakukan dengan melakukan wawancara dan pertimbangan logis untuk menentukan komponen-komponen yang terlibat dalam penerapan sistem manajemen mutu di perusahaan. Ultimate goal dalam penelitian ini adalah mengurangi komplain konsumen dengan penerapan sistem manajemen mutu. Ultimate goal ini dijadikan sebagai hal yang harus dicapai perusahaan dalam penerapan HACCP. Hal ini bertujuan untuk memperbaiki penerapan HACCP di perusahaan agar terciptanya sistem HACCP yang lebih baik lagi dari penerapan sebelumnya.

Untuk mencapai ultimate goal permasalahan yang ada harus diuraikan. Kriteria, subkriteria, dan tujuan yang diungkap pada kasus ini berupa sistem manajemen mutu yang didapat berdasarkan pengamatan lapang dan diskusi dengan substansi yang paling penting dalam penerapan sistem manajemen mutu. Fokus identifikasi permasalahan tersusun beberapa tingkatan seperti tingkatan satu adalah fokus sasaran atau ultimate goal, tingkat kedua adalah faktor atau kriteria masalah, tingkat tiga adalah aktor atau pelaku, tingkat keempat adalah objektif atau tujuan yang ingin dicapai yaitu sesuai denganFaktor-faktor yang diidentifikasi dan berpengaruh dalam pemenuhan ultimate goal penerapan sistem manajemen mutu adalah :

Faktor-faktor yang diidentifikasi dan berpengaruh dalam pemenuhan ultimate goal penerapan sistem manajemen mutu adalah :

1. Terintegrasinya Sistem Manajemen Mutu

2. Pengetahuan sumber daya manusia.

3. Sarana dan Prasarana.

4. Kebijakan Mutu

Aktor yang berperan dalam pemenuhan faktor-faktor pada penerapan sistem manajemen mutu diperusahaan adalah:
1. Tim HACCP

2. Manager QA/QC

3. Karyawam Produksi

Tujuan yang dapat dipenuhi oleh para aktor yang teridentifikasi yaitu

1. Produk dengan mutu baik dan aman bagi konsumen.

2. Peningkatan sistem manajemen mutu

Alternatif yang dapat dilaksanakan untuk mencapai tujuan yang ada dalam pemenuhan penerapan sistem HACCP pada perusahaan adalah :

1. Mempertahankan dan menjadikan mutu sebagai keunggulan produk dalam pasar global

2. Menjaga sistem manajemen mutu terhadap proses produksi untuk mengurangi adanya komplain konsumen

3. Mengevaluasi sistem manajemen mutu yang ada dan memperbaiki sarana dan prasarana ruang produksi sesuai dengan persyaratan HACCP

4. Mengadakan pelatihan Sistem Manajemen Mutu kepada seluruh karyawan berdasarkan tingkatannya

5. Melaksanakan uji pembanding hasil laboratorium guna memvalidasi kualitas produk dan meminta dokumen mutu pada proses pembelian ingredients

6. Mempertahankan dan meningkatkan kualitas produk untuk menjaga kepercayaan konsumen

7. Memperketat kerja seluruh komponen karyawan dalam menjaga mutu produk serta berorientasi kepada peningkatan mutu dengan kebijakan mutu yang telah ditetapkan

8. Melakukan kerjasama kemitraan dengan supplier sehingga produk yang diberikan dapat terjaga kualitas mutunya.

\section{b. Analisa Faktor Hierarki}

Hasil dari responden ke-1,3,4,5, dan 9 adalah menyatakan bahwa alternatif strategi mengevaluasi sistem manajemen mutu yang ada dan memperbaiki sarana dan prasarana ruang produksi sesuai dengan persyaratan HACCP, alternatif ini memiliki bobot tertinggi sebesar 0.19, 0.29, 0.18, 0.21, dan 0.17. Hasil dari responden ke-2 menyatakan bahwa alternatif strategi memperketat kerja seluruh komponen karyawan dalam menjaga mutu produk serta berorientasi kepada peningkatan 
mutu dengan kebijakan mutu yang telah ditetapkan dengan bobot sebesar 0.16. Hasil dari responden ke-6 menyatakan bahwa alternatif strategi mengadakan pelatihan Sistem Manajemen Mutu kepada seluruh karyawan berdasarkan tingkatannya dengan bobot

sebesar 0.23 . Hasil dari responden ke-7 dan 8 menyatakan bahwa alternatif strategi menjaga sistem manajemen mutu terhadap proses produksi untuk mengurangi adanya komplain konsumen dengan bobot sebesar 0.17 dan 0.18 .

Tabel 1 Alternatif Strategi Responden.

\begin{tabular}{|c|c|c|c|c|c|c|c|c|c|}
\hline \multirow[t]{2}{*}{ Alternatif Strategi } & \multicolumn{9}{|c|}{ Responden } \\
\hline & 1 & 2 & 3 & 4 & 5 & 6 & 7 & 8 & 9 \\
\hline $\begin{array}{l}\text { Mempertahankan dan menjadikan mutu } \\
\text { sebagai keunggulan produk dalam pasar } \\
\text { global }\end{array}$ & 0.12 & 0.12 & 0.11 & 0.10 & 0.11 & 0.13 & 0.12 & 0.15 & 0.15 \\
\hline $\begin{array}{l}\text { Menjaga system manajemen mutu } \\
\text { terhadap proses produksi untuk } \\
\text { mengurangi adanya complain konsumen }\end{array}$ & 0.11 & 0.13 & 0.13 & 0.15 & 0.14 & 0.14 & 0.17 & 0.18 & 0.11 \\
\hline $\begin{array}{l}\text { Mengadakan pelatihan system manajemen } \\
\text { mutu kepada seluruh karyawan } \\
\text { berdasarkan tingkatannya }\end{array}$ & 0.16 & 0.11 & 0.08 & 0.10 & 0.15 & 0.23 & 0.15 & 0.13 & 0.13 \\
\hline $\begin{array}{l}\text { Melaksanakan uji perbandingan hasil } \\
\text { laboratorium guna memvalidasi kualitas } \\
\text { prosuk dan meminta dokumen mutu pada } \\
\text { proses pembelian ingredients }\end{array}$ & 0.10 & 0.14 & 0.05 & 0.18 & 0.70 & 0.08 & 0.05 & 0.06 & 0.07 \\
\hline $\begin{array}{l}\text { Meningkatkan kualitas produk untuk } \\
\text { menjaga kepercayaan konsumen }\end{array}$ & 0.14 & 0.13 & 0.16 & 0.12 & 0.13 & 0.09 & 0.13 & 0.11 & 0.16 \\
\hline $\begin{array}{l}\text { Memperketat kerja seluruh karyawan } \\
\text { dalam menjaga mutu produk serta } \\
\text { berorientasi kepada peningkatan mutu } \\
\text { dengan kebijakan mutu yang telah } \\
\text { ditetapkan }\end{array}$ & 0.14 & 0.16 & 0.14 & 0.11 & 0.15 & 0.17 & 0.16 & 0.16 & 0.17 \\
\hline $\begin{array}{l}\text { Melakukan kerjasama kemitraan dengan } \\
\text { supplier sehingga produk yang diberikan } \\
\text { dapat terjaga kualitas mutunya }\end{array}$ & 0.10 & 0.10 & 0.03 & 0.05 & 0.38 & 0.05 & 0.08 & 0.07 & 0.05 \\
\hline $\begin{array}{l}\text { Mengevaluasi sistem manajemen mutu } \\
\text { yang ada dan memperbaiki sarana dan } \\
\text { prasarana ruang produksi sesuai dengan } \\
\text { persyaratan HACCP }\end{array}$ & 0.19 & 0.13 & 0.30 & 0.18 & 0.21 & 0.12 & 0.14 & 0.14 & 0.17 \\
\hline
\end{tabular}

\section{c. Penentuan Strategi Sistem Penjamin Mutu Untuk Implementasi}

Kebijakan mutu pada suatu perusahaan haruslah dibuat sesuai dengan tujuan yang akan dicapai oleh perusahaan dan menjalankan kebijakan mutu yang telah dibuat dengan konsisten agar memperoleh kepercayaan konsumen dan menghasilkan produk yang berkualitas tinggi.

Tabel 2. Bobot prioritas faktor

\begin{tabular}{lcc}
\hline \multicolumn{1}{c}{ Faktor } & Bobot & Prioritas \\
Terintegrasinya sistem & 0.207 & 3 \\
manajemen mutu & & \\
Pengetahuan sumber & & \\
daya manusia & 0.097 & 4 \\
Sarana dan prasarana & 0.327 & 2 \\
Kebijakan mutu. & 0.369 & 1 \\
\hline
\end{tabular}

Tabel 3. Bobot prioritas actor

\begin{tabular}{llc}
\hline \multicolumn{1}{c}{ Aktor } & Bobot & Prioritas \\
\hline Tim HACCP & 0.386 & 2 \\
Manager QA dan QC & 0.367 & 3 \\
Karyawan Produksi & 0.444 & 1 \\
\hline
\end{tabular}

Hasil analisis aktor - aktor yang paling berperan penting dalam penentuan strategi penerapan sistem manajemen mutu pada industri value added rajungan adalah dengan bobot prioritas sebesar 0, 444 yaitu pada aktor karyawan produksi. Karyawan produksi secara langsung mengendalikan HACCP. Hal ini sejalan dengan Sutrisno (2013) yang berpendapat bahwa karyawan produksi merupakan aktor yang menjalani proses produksi dikondisi sebenarnya, kegiatan mutu berawal dari pengendalian mutu produk oleh karyawan produksi itu sendiri. Sehingga karyawan produksi sangat berperan dalam pelaksana sistem mutu keamanan pangan HACCP. 
Hasil analisis tujuan-tujuan yang paling berperan penting dalam penentuan strategi penerapan sistem manajemen mutu pada industri value added rajungan memiliki prioritas yang sama untuk mencapai kepuasan konsumen dan mencegah terjadinya komplain konsumen.

Setelah memperhatikan secara menyeluruh mengenai faktor, aktor dan tujuan yang hendak dicapai dari strategi penerapan

Tabel 5 Bobot prioritas alternatif strategi.

\begin{tabular}{lcc}
\multicolumn{1}{c}{ Alternatif Strategi } & Bobot & Prioritas \\
\hline $\begin{array}{l}\text { Mempertahankan dan menjadikan mutu sebagai keunggulan produk dalam pasar } \\
\text { global }\end{array}$ & 0.117 & 5 \\
\hline $\begin{array}{l}\text { Menjaga sistem manajemen mutu terhadap proses produksi untuk mengurangi } \\
\text { adanya komplain konsumen }\end{array}$ & 0.138 & 4 \\
\hline $\begin{array}{l}\text { Mengadakan pelatihan Sistem Manajemen Mutu kepada seluruh karyawan } \\
\text { berdasarkan tingkatannya }\end{array}$ & 0.104 & 7 \\
\hline $\begin{array}{l}\text { Melaksanakan uji pembanding hasil laboratorium guna memvalidasi kualitas produk } \\
\text { dan meminta dokumen mutu pada proses pembelian ingredients }\end{array}$ & 0.106 & 6 \\
\hline $\begin{array}{l}\text { Mempertahankan dan meningkatkan kualitas produk untuk menjaga kepercayaan } \\
\text { konsumen }\end{array}$ & 0.139 & 3 \\
\hline $\begin{array}{l}\text { Memperketat kerja seluruh komponen karyawan dalam menjaga mutu produk serta } \\
\text { berorientasi kepada peningkatan mutu dengan kebijakan mutu yang telah ditetapkan }\end{array}$ & 0.141 & 2 \\
\hline $\begin{array}{l}\text { Melakukan kerjasama kemitraan dengan supplier sehingga produk yang diberikan } \\
\text { dapat terjaga kualitas mutunya }\end{array}$ & 0.060 & 8 \\
\hline $\begin{array}{l}\text { Mengevaluasi sistem manajemen mutu yang ada dan memperbaiki sarana dan } \\
\text { prasarana ruang produksi sesuai dengan persyaratan HACCP }\end{array}$ & 0.195 & 1 \\
\hline
\end{tabular}

sistem manajemen mutu, maka dilakukan analisis terhadap strategi atau alternatif yang paling tepat untuk dijadikan prioritas. Alternatif yang paling dominan dengan bobot prioritas sebesar 0,195 terhadap strategi penerapan adalah strategi untuk mengevaluasi sistem manajemen mutu yang ada dan memperbaiki sarana dan prasarana ruang produksi sesuai dengan persyaratan HACCP.

\section{d. Penerapan Hierarki Strategi Sistem Manajemen Mutu}

Perusahaan telah melakukan perbaikan sistem manajemen mutu untuk mengurangi komplain konsumen berdasarkan hasil prioritas AHP dari para pakar. Penerapan ini dilaksanakan selama 80 hari dari proses pembuatan produk hingga dilakukan ekspor, selama waktu tersebut dengan penerapan sistem HACCP yang telah diperbaharui berdasarkan evaluasi tidak terdapat komplain konsumen. Pelaksanaan BRC perlu adanya penerapan sistem yang direcord dan didokumentasikan. HACCP dan BRC berjalan saling beriringan, hal ini dikarenakan keduanya sama-sama menjaga keamanan pangan (Kafel et al, 2013).

\section{Pelaksanaan Implementasi}

Tujuan dari implementasi ini untuk mengevaluasi dan menyempurnakan suatu tahapan proses sehingga dapat mengurangi adanya komplain konsumen. Penerapan flow chart produksi pada gambar 1 merupakan salah satu implementasi penerapan sistem jaminan mutu HACCP. Tujuan dari penerapan HACCP dalam suatu industri pangan adalah untuk mencegah terjadinya bahaya sehingga dapat dipakai sebagai jaminan mutu pangan guna memenuhi tututan konsumen. HACCP bersifat sebagai sistem pengendalian mutu sejak bahan baku dipersiapkan sampai produk akhir diproduksi masal dan didistribusikan. Evaluasi HACCP secara terus menerus dapat mengurangi komplain konsumen.

Berdasarkan hasil evaluasi strategi dengan bobot prioritas tertinggi, implementasi yang dilaksanakan dalam mengevaluasi sistem jaminan mutu dan memperbaiki sarana prasarana dengan menyempurnakan proses produksi. Identifikasi pelaksanaan implementasi ini dilihat dari masalah yang sering muncul yaitu adanya benda asing pada produk. Benda asing pada produk ini berasal dari karywan produksi yang tidak teliti dalam melakukan pekerjannya. Proses produksi perlu dilakukan secara teliti pada setiap tahapan CP dan $\mathrm{C}$.

CP yang dapat menyebabkan bahaya keamanan pangan serta timbulnya komplain konsumen. Tahapan CP berada pada setiap titik tahap atau prosedur pada suatu sistem produksi makanan yang dapat mengendalikan faktor bahaya mikrobiologi, kimia atau fisika. Tahapan CCP berada setiap titik, tahap atau prosedur pada suatu sistem produksi makanan yang jika tidak terkendali dapat mengakibatkan resiko kesehatan yang tidak diinginkan atau setiap titik, tahap atau prosedur yang jika dikendalikan dengan baik dan benar dapat mencegah, menghilangkan atau mengurangi adanya bahaya. Tahapan CP dan CCP dapat dilihat pada flowchart proses. 
Adanya perubahan proses produksi maka proses pengendalian dan perekaman juga akan berubah. Sebelumnya proses produksi value added rajungan ruang proses tidak diberikan lampu UV dan langsung dilakukan proses final checking. Sehingga memungkinkan banyaknya benda asing terikut dalam proses produksi yang berpotensi menyebabkan adanya komplain konsumen. Sarana dan prasarana yang buruk seperti lantai yang pecah, dan peralatan pecah dapat pula berpotensi menjadi bahaya fisik pada produk yang menyebabkan komplain. Adanya kontaminasi benda asing dari serpihan bangunan maupun yang lainnya tidak terlihat pada saat proses sortir karena partikel yang terlalu kecil dan warna yang hampir sama dengan produk.

Tindakan perbaikan yang dilakukan pada ruang proses diberikan penambahan ruang blacklight dan pemberian lampu UV sebagai final checking dalam pengecekkan kualitas daging dari serpihan benda asing, sehingga cahaya UV akan berpendar apabila terdapat benda asing. Cahaya yang berpendar akibat pantulan sinar UV pada daging memudahkan karywan produksi dalam proses sortir. Operator akan lebih teliti lagi dalam melakukan proses sorting sehingga daging yang akan diproses lebih lanjut dapat terhindar dari bahaya fisik pangan. Peralatan proses produksi secara bertahap sudah mulai berangsur diganti yang lebih baik serta ruang proses sudah mengalami perbaikan.

Perubahan yang dilakukan hanya satu tahapan proses namun tahapan inilah yang mempengaruhi proses selanjutnya untuk keamanan pangan dan menghindari komplain konsumen. Pada tahapan ini seluruh daging rajungan disortir baik dalam bentuk filth, shell, ataupun benda asing yang terikut. Adanya lampu UV sangat membantu pekerja dalam melakukan tahapan sortir sehingga sortir lebih akurat dalam pemilihannya.

Perubahan flow chart proses produksi mempengaruhi perubahan HACCP pada perusahaan. Hal ini sejalan dengan Ababio (2015), HACCP bersifat preventif sesuai kebutuhan oleh perusahaan dan diterapkan berdasrakan sistem yang ada id industri sehingga lebih kompleks dalam melaksanakan dan pengendaliannya. HACCP kini telah menjadi bagian penting dari semua standar keamanan pangan yang diterima secara internasional. Implementasi HACCP dengan perubahan flowchart membutuhkan pengendalian dan revisi perekaman proses. Menurut Beyza dan Canan (2013), setiap sistem HACCP mengakomodasi perubahan seperti kemajuan dalam rancangan peralatan, prosedur pengolahan atau perkembangan teknologi. HACCP dapat 244 diterapkan pada seluruh rantai pangan dari produk primer sampai pada konsumsi akhir dan penerapannya harus dipedomani dengan bukti secara ilmiah terhadap resiko kesehatan manusia.

Terdapat penurunan komplain konsumen apabila pelaksanaan proses produksi sesuaidengan flow chart dan menjaga titik kritis produksi yang telah ditetapkan. Selain itu sadarnya karyawan akan keamanan pangan dan pengetahuan karyawan tentang sistem manajmen mutu dapat menurunkan komplain konsumen dengan menjaga proses produksi dari penerimaan bahan baku hingga proses ekspor. Tidak adanya komplain konsumen maka permintaan akan produksi akan semakin meningkat dan dari keuntungan tersebut dapat mensejahterakan pula karyawan yang bekerja pada industri ini.

Tidak adanya komplain pada perusahaan biaya ganti rugi maupun biaya operasional tidak masuk pada anggaran biaya sehingga perusahaan dapat menyimpan biaya. Jika dibandingkan jumlah komplain di tahun 2017 semester pertama mengalami penurunan yang signifikan pada semester kedua. Pada tahun 2017 semester pertama sebanyak 4 komplain dan semeter kedua sebanyak 0 komplain. Hal ini menunjukkan implementasi yang telah dilaksanakan berjalan efektif dengan penurunan komplain sebanyak $100 \%$. Berkurangnya komplain tersebut diperkirakan dapat menghindari kerugian akibat komplain konsumen sebesar Rp. 400.000 .000 (empat ratus juta) lebih per tahun yang dihitung berdasarkan klaim dari konsumen, sehingga dapat disimpulkan implementasi strategi yang dilakukan untuk mengurangi komplain konsumen berjalan secara efisien.

\section{KESIMPULAN}

Sejak menerapkan perbaikan SMMP komplain konsumen tidak terjadi selama enam bulan terakhir. Hal ini menunjukkan bahwa perusahaan dapat menghindari kerugian finansial berupa klaim akibat komplain konsumen sebesar Rp. 400.000.000 (empat ratus juta) per tahun.

\section{UCAPAN TERIMAKASIH}

Ucapan terimakasih saya sampaikan kepada perusahaan yang telah bersedia untuk dilakukan penelitian serta semua pihak yang mendukung penelitian ini. 


\section{DAFTAR PUSTAKA}

Ababio. (2015). An Investigation Into the Incidence of Food Pathogenic Bacteria In Senior Secondary School Canteens In the Ashanti Region of Ghana And the Effect of Food Safety Interventions. (Tesis) University of Lincoln. Inggris. 321 p.

Anggraini dan Yudhastuti. (2014). Penerapan Good Manufactoring Practices pada Industri Rumah Tangga Kerupuk Teripang di Sukolilo Surabaya. Jurnal Kesehatan Lingkungan. 7 (2) : 148-158.

Basith, A., A. Sutrisno, dan Wijaya. (2013). Analisis Strategi Penerapan Sistem Manajemen Keamanan Pangan HACCP (Hazard Analysis and Critical Control Points) di PT. Sierad Produce Tbk. Parung. Jurnal Manajemen dan Organisasi. 4(2): 73-90.

Beyza and Canan. (2013). Is HACCP a Difficult Food Safety System to Implement? Jurnal Biologi Environmental. SCI 7(19): 33-38.

CAC. (2003). Recommended international code of practice General principles of food hygiene.https://www.mhlw.go.jp/english/t opics/importedfoods /guideline/dl/04.pdf. Diakses pada tanggal 30 November 2018.

Daulay, S.S. (2016). Hazard Analysis Critical Control Point (HACCP) dan Implementasinya Dalam Industri Pangan. Widyaiswara Madya Pusdiklat Industri. www.kemenperin.go.id/.../HACCP-danImplementasinya-Dalam-Industri-

Pangan. Diakses pada tanggal 3 November 2016. $22 \mathrm{hlm}$.

Dimitrios P. K, Evangelos L.P., and Panagiotis D.K. (2013). Measuring the effectiveness of the HACCP Food Safety Management System. Journal Food Control. 33(2), 505-513.

Fachry, M. Probowati, dan A. Triharjono. (2013). Evaluasi Prosedur Standar Sanitasi Kerupuk Amplang di UD Sarina. Jurnal Agrointek. 7 (2): 76-83

Fathonah, S. (2005). Hygiene Sanitasi Makanan. Semarang. Universitas Negeri Semarang Press.

Grigg, N. P., and McAlinden, C. (2001). A New Role For ISO 9000 in The Food Industry? Indicative Data From the UK and Mainland Europe. British Food Journal. 103(9), 644-656.
Hadiwiarjo, Bambang, Wibisono, Sulistijarningsih (2000). Memasuki Pasar Internasional dengan ISO 9001. Gahlia Indonesia. Jakarta. $162 \mathrm{hlm}$.

Herdiana, D.S. (2015). Sardines Product Quality Control in Terms of HACCP To Improve Food Security in Blambangan Foodpacker Indonesia Company Limited, Banyuwangi. International Food Research Journal. 22(4): 1507-1512.

Hermansyah, M., Pratikto, R. Soenoko, dan N.W. Setyanto. (2013). Hazard Analysis and Critical Control Point (HACCP) Produksi Maltosa Dengan Pendekatan Good Manufacturing Practice (GMP). Jurnal Jemis. 1(1): 14-20.

Jadi. A. (2016). Enhancing the Monitoring Systems of SFDA in Saudi Arabia Markets. International Journal of Software Engineering \& Applications. 17 (4): 31-45.

Kafel, P. P. Niwicki, and S. Karel. (2013). Selected Requirements of Integrated Management Systems Based On Pas 99 Specification. Journal Quality Research 7(1):97-106.

Puspitasari, D. (2012). Menerapkan Prinsip Praktek Profesional Dalam Bekerja. Inti Prima Promosindo. Jakarta. $114 \mathrm{hlm}$.

Rafeeque, M. and Sekharan, M.N. (2017). Approch To Adoption of Multiple Food Safety. Journal of Supply Chain Management System. 6 (4):11-21

Redmond, E.C. and C. J. Griffith. (2003). Consumer Food Handling in the Home: A Review of Food Safety Studies. J. of Food Protection. 66 (1):130-161.

Ricci, A. (2017). Hazard Analysis Approaches For Certain Small Retail Establishments in View of The Application of Their Food Safety Management Systems. Journal EFSA. 15 (3):1-52.

Sherif, M. (2013). Barriers To Compliance With International HACCP Regulations: A Whole Chain Approach to the National Fisheries Food Safety Management System of Sierra Leone. (Disertasi) Salford Business School. Salford University. Gretaer Manchester. United Kingdom. 358 p.

Sudibyo, A. I.S. Surono, dan P. Waspodo. ( 2016). Pengantar Keamanan Pangan. Deepublish. Yogyakarta. $240 \mathrm{hlm}$.

Surahman, D.N dan R. Ekafitri. (2014). Kajian HACCP (Hazard Analysis and Critical Control Point) Pengolahan Jambu Biji Di 
Pilot Plant Sari Buah UPT. B2PTTG LIPI SUBANG. Jurnal Agritech. 34 (2) : 266-276.

Sutresni, N. M.S. Mahendra. dan I.W.R. Iryanta. (2016). Penerapan Hazard Analysis Critical Control Point (HACCP) Pada Proses Pengolahan Produk Ikan Tuna Beku di Unit Pengolahan Ikan Pelabuhan Benoa - Bali. Jurnal Echotropic. 10 (1): 41-45.

Sutrisno, A. (2013). Analisis Strategi Penerapan Sistem Manajemen Keamanan Pangan HACCP (Hazard Analysis Critical Control Point) di PT. Sierad Produce Tbk.
Parung. (Skripsi) Fakultas Ekonomi dan Manajemen. IPB. Bogor. $170 \mathrm{hlm}$.

Trilaksani, W. (2011). Pengembangan Sistem Manajemen Mutu Terpadu Produk Tuna Ekspor: Suatu Kajian Fungsi Manajemen Mutu dan Keamanan Produk di Muara Baru, DKI JAKARTA. (Disertasi). Pascasarjana Teknologi Kelautan. Institut Pertanian Bogor. $565 \mathrm{hlm}$.

Tsaniyah, H. (2015). Pengendalian Proses Produksi Bahan Pakan Bungkil Sawit Dalam Perspektif Keamanan Pangan. Jurnal OE. 7 (2): 121-131. 
Evaluasi Sistem Manajemen Mutu Produk Rajungan "Value Added" untuk Mengurangi Komplain Konsumen di Pabrik Pengolahan Rajungan Value Added Lampung

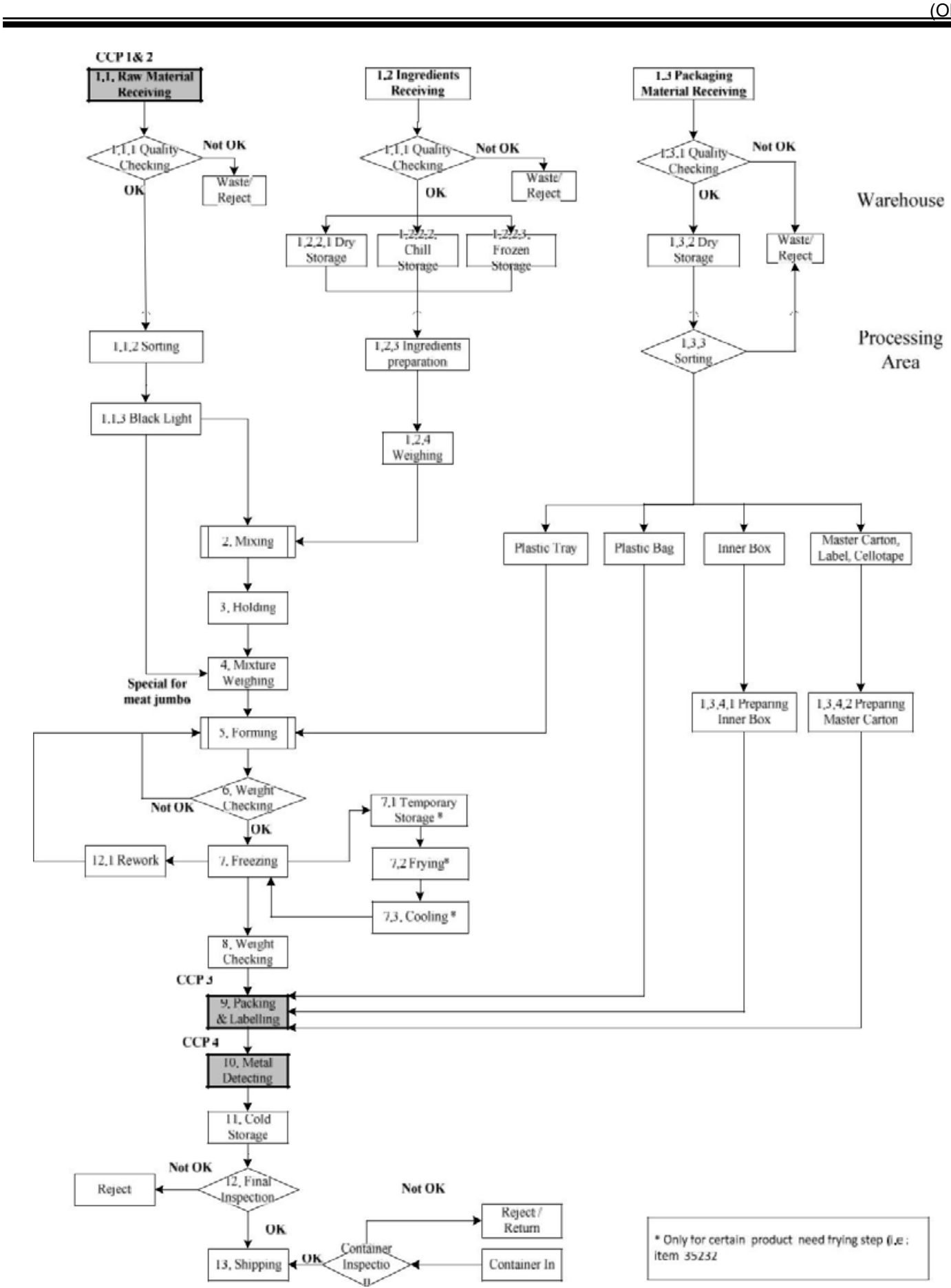

Gambar 1 Flow chart pengolahan rajungan 